\title{
Regimes de Financiamento, Risco Crescente do Endividamento e Fragilidade Financeira
}

\author{
Gilberto Tadeu Lima \\ Antonio J. A. Meirelles
}

\author{
FEA/USP - Departamento de Economia \\ UNICAMP - Faculdade de Engenharia de Alimentos
}

\begin{abstract}
RESUMO
Elabora-se um modelo macroeconômico de curto prazo na tradição pós-keynesiana, no qual a oferta de crédito é endógena e o grau de endividamento das firmas é explicitamente modelado. Relacionam-se as condições de vigência dos regimes minskyanos de financiamento hedge, especulativo ou Ponzi - não somente ao grau de endividamento e à taxa de juros, mas, inclusive, aos parâmetros da função investimento desejado da firmas e à propensão a poupar dos capitalistas produtivos e financeiros.
\end{abstract}

\section{PALAVRAS-CHAVE}

endividamento, risco crescente, fragilidade financeira

ABSTRACT

It is developed a short-run macromodel in the post-keynesian tradition, in which credit supply is endogenous and firms' debt position is explicitly modeled. The conditions under which each one of the minskyan financing regimes will prevail are related not only to the degree of indebtedness and the level of interest rate, but also to the parameters of firms' desired investment function and the saving propensity of productive and financial capitalists.

KEY WORDS

indebtedness, increasing risk, financial fragility

JEL Classification

EI2, G00

EST. ECON., SÃO PAULO, V. 35, N. 2, P. 317-334, ABRIL-JUNHO 2005 


\section{INTRODUÇÃO}

O presente artigo desenvolve um modelo macroeconômico de curto prazo na tradição pós-keynesiana de abordagem da acumulação de capital produtivo e da distribuição funcional da renda, no qual a oferta de moeda de crédito é endógena - e, portanto, a taxa de juros é exógena ao processo de determinação, via princípio da demanda efetiva, do produto e renda - e o grau de endividamento do setor produtivo com o financeiro é explicitamente modelado.

O investimento desejado das firmas - e, logo, a acumulação de capital físico - é viabilizado pela obtenção de crédito com o setor financeiro e depende positivamente da taxa de lucro, negativamente da taxa de juros e, em conformidade com o sinal correspondente, da diferença entre o grau de endividamento efetivo e o desejado como máximo pelas firmas. Este último argumento, inspirado no princípio do risco crescente elaborado por Michal Kalecki, indica que um grau de endividamento superior (inferior) a um grau crítico predeterminado, sendo ambos expressos como relação entre dívida acumulada e estoque de capital físico, provoca um impacto negativo (positivo) sobre os planos de acumulação de capital físico das firmas. Mais precisamente, o modelo desenvolvido no compasso deste artigo associa um risco crescente não diretamente ao volume de investimento em si, como na elaboração original de Kalecki, mas, sim, ao endividamento das firmas como proporção do estoque de capital físico e, portanto, indiretamente ao nível de investimento por elas desejado como proporção desse mesmo estoque.

Nesse contexto, são estabelecidas rigorosamente as condições formais que definem os diversos regimes de endividamento - hedge, especulativo ou Ponzi - sob os quais as firmas podem vir a operar, conforme a taxonomia elaborada por Minsky $(1975,1982)$. Além disso, é analisada formalmente a dependência da propensão a cada um desses regimes em relação não somente ao grau de endividamento e à taxa de juros vigentes, mas, inclusive, aos parâmetros que governam os planos de acumulação de capital físico das firmas e à propensão a poupar de capitalistas produtivos e financeiros. Com o estabelecimento rigoroso das condições formais de vigência dos regimes minskyanos de financiamento, portanto, torna-se possível analisar os impactos de variaçóes naqueles parâmetros, não apenas sobre a propensão do setor produtivo a operar sob cada um desses regimes, mas, também, e ao mesmo tempo, sobre os níveis de utilização da capacidade produtiva e das taxas de lucro total e crescimento econômico.

O restante do artigo está organizado da seguinte forma. A seção 1 descreve a estrutura formal do modelo, enquanto a seção 2 o resolve explicitamente e analisa seu comportamento em nível de estática-comparativa. A seção 3, por sua vez, estabelece as condições formais que definem os vários regimes minskyanos de endividamento, com base no que são avaliados os impactos de certas mudanças paramétricas sobre a propensão do setor produtivo a cada um desses regimes, bem como sobre os níveis de utilização da capacidade produtiva instalada e das taxas de lucro total e crescimento econômico. A última seção reprisa então os principais resultados derivados ao longo do artigo. 


\section{ESTRUTURA DO MODELO}

Modela-se uma economia fechada e isenta de atividades fiscais por parte do governo. Um único bem é produzido, sendo ele utilizável tanto para consumo como para investimento. Apenas dois fatores são utilizados em sua produção, capital e trabalho, combinados por meio de uma tecnologia de coeficientes fixos.

As firmas produzem de acordo com a demanda efetiva, sendo modelado aqui apenas a situação em que esta é insuficiente para garantir a plena utilização do capital físico instalado. Entretanto, nenhum excesso de mão-de-obra é empregado, posto que não existem contratos de trabalho de longa duração. Os planos de acumulação de capital das firmas são representados pela seguinte equação:

$$
g^{d}=\alpha+\beta r-\gamma i-\varphi\left(\delta-\delta_{c}\right)
$$

onde $\alpha, \beta, \gamma$ e $\varphi$ são parâmetros positivos, $g^{d}$ é o investimento das firmas como proporção do estoque de capital físico, $K, r$ é a taxa de lucro total, definida como o fluxo total de lucros líquidos, $R$, normalizado pelo estoque de capital físico, enquanto $i$ é a taxa de juros. Por seu turno, $\delta$ é o endividamento efetivo das firmas com o setor financeiro como proporção do estoque de capital físico, enquanto $\delta_{c}$, doravante endividamento desejado, é o nível predeterminado - exogenamente - desta razão que as firmas desejam como máximo. Seguimos Robinson (1962), Kalecki (1971), Rowthorn (1981) e Dutt (1994) na suposição de que o investimento desejado depende positivamente da taxa de lucro sobre o capital físico, posto que esta representa um indicador da lucratividade esperada e, além disso, facilita a obtenção de recursos externos. O segundo argumento, por sua vez, captura o efeito (negativo) da taxa de juros, enquanto expressão do custo do capital financeiro, no que seguimos Dutt (1990-91, 1994). Quanto ao último argumento, assumidamente inspirado no princípio do risco crescente de Michal Kalecki, o suposto é o de que um grau de endividamento efetivo inferior (superior) ao desejado como máximo exerce um efeito positivo (negativo) sobre a decisão de investimento. ${ }^{1}$

1 Queremos ressaltar que este último argumento deve ser interpretado como algo inspirado no - e não representativo do - princípio do risco crescente elaborado por Michal Kalecki (1937). Em sua intuição original, o princípio estabelece que o risco marginal (percebido pela firma) do investimento cresce com o montante deste - basicamente pela maior ameaça à posição de riqueza do empreendedor no caso de insucesso do investimento e pelo maior perigo de iliquidez representado pela manutenção de uma maior parcela da riqueza sob a forma de ativos de capital. Posto que o montante investido pela firma é dado pela igualação da eficiência marginal do investimento com a soma entre esse risco marginal e a taxa de juros, é plenamente possível, portanto, que o investimento cesse já em um ponto em que ainda existem projetos que renderiam uma taxa de retorno acima da taxa de juros (LIMA, 1999). Assim, a especificação adotada no modelo deste artigo associa um risco crescente não diretamente ao volume de investimento em si, mas, sim, ao nível de endividamento como proporção do estoque de capital físico e, portanto, indiretamente ao investimento desejado como proporção desse mesmo estoque. 
A economia é habitada por duas classes sociais, capitalistas e trabalhadores. Seguindo a tradição pós-keynesiana de economia política inaugurada por Kalecki (1971), assumese que essas classes adotam diferentes comportamentos de consumo e poupança. Os trabalhadores ofertam mão-de-obra e recebem apenas salários, os quais são totalmente gastos em consumo. Os trabalhadores estão sempre em excesso de oferta, com seu número crescendo a uma taxa exógena. Por seu turno, o conjunto dos capitalistas aufere sob a forma de lucros todo o excedente sobre os salários. Assim sendo, a divisão funcional da renda entre trabalhadores e capitalistas é dada por:

$$
X=V L+r K
$$

onde $X$ é o nível de produto, $V$ é o salário real e $L$ é o nível de emprego. Porém, o agregado de lucros gerado pela economia é dividido entre capitalistas de dois setores, $o$ produtivo e o financeiro, segundo a equação abaixo:

$$
r K=r_{p} K+r_{f} K
$$

onde $r_{p}$ representa a fração da taxa de lucro total que cabe ao setor produtivo e $r_{f}$ a fração da taxa de lucro total que cabe ao setor financeiro, ambas expressas como fração do estoque de capital físico. Sendo assim, os lucros dos capitalistas financeiros representam uma dedução do fluxo total de lucros gerado pelo estoque de capital físico, numa proporção dada pelo estoque de dívida dos capitalistas produtivos com os capitalistas financeiros e pela taxa de juros vigente. Enquanto os capitalistas produtivos poupam uma fração $s_{p}$ de sua parcela do total de lucros, os capitalistas financeiros poupam uma fração $s_{f}$ de sua parcela correspondente.

Empregando-se a eq. (2), a taxa de lucro total da economia é dada por:

$$
r=(1-V a) u
$$

onde $a$ é a relação trabalho-produto, $(1-V a)$ é a participação total dos lucros na renda e $u=X / K$ é o grau de utilização da capacidade produtiva. Posto que assumimos a constância da razão entre o produto potencial e o estoque de capital, podemos então identificar o grau de utilização da capacidade produtiva com a relação produto-capital. ${ }^{2}$ Para efeito de focalização e redução da dimensionalidade do modelo, assume-se que a

2 Por necessidade de focalização, o presente modelo de curto prazo não considera a ocorrência de mudança tecnológica. Para dois modelos macrodinâmicos pós-keynesianos de utilização e crescimento da capacidade produtiva que incorporam a ocorrência de inovações tecnológicas poupadoras de trabalho, porém não formalizam o lado monetário, vide LIMA $(2000,2004)$. No primeiro, com um espírito (neo-)schumpeteriano, a taxa de inovação depende não-linearmente da concentração de mercado. No segundo, a taxa de inovação varia não-linearmente com a parcela dos salários na renda. Em ambos, a não-linearidade envolvida gera possíveis equilíbrios duplos e trajetórias cíclicas para as variáveis endógenas. 
parcela total dos lucros na renda está predeterminada, de maneira que a taxa de lucro total somente pode variar em função de mudanças na utilização da capacidade produtiva. Assume-se, portanto, que a relação trabalho-produto, o salário nominal, o nível de preço e, com isso, o salário real estão igualmente predeterminados. Além disso, esse valor (normalizado) do nível de preço é igual à unidade.

No tocante ao processo endógeno de criação de moeda de crédito, assume-se, de uma forma estilizada, que o sistema bancário atua como tomador de preço e fixador de quantidade no mercado de captação de recursos (cujo preço é definido, em larga medida, pela autoridade monetária, por meio do juro básico), e como tomador de quantidade (a demandada pelo setor produtivo, de acordo com suas decisóes de gasto) e fixador de preço (com base no mark-up sobre o custo de captação) no mercado de concessão de crédito. Assim, os bancos encontram-se em condições de atender à demanda de crédito do setor produtivo a um preço compatível com aquele que represente o mark-up pretendido sobre o custo de captação, de acordo com seus critérios de lucratividade, aversão ao risco e preferência pela liquidez. Por outro lado, procuram captar os recursos necessários e/ou gerar as reservas adequadas àquelas decisões de fornecimento de crédito. ${ }^{3}$

O grupo de capitalistas financeiros é composto de rentistas e banqueiros, ambos tendo a mesma propensão a poupar, $s_{f}$. Os ativos retidos pelos rentistas são constituídos pelos certificados de depósitos bancário e os créditos emitidos ao setor produtivo representam os ativos mantidos em carteira pelos banqueiros. Assume-se que a riqueza rentista não captada pelos bancos permanece ociosa e sobre ela não incide qualquer rendimento, de maneira que a renda do setor financeiro como um todo, incluindo banqueiros e rentistas, é exatamente a contraparte do serviço da dívida do setor produtivo. ${ }^{4}$ Como proporção do estoque de capital físico, o grau de endividamento do setor produtivo é dado por:

3 Nesse sentido, o fato de os bancos estarem em condições de satisfazer plenamente a demanda por empréstimos à taxa de juros vigente, seja por operarem com excesso de reservas ou por poderem recorrer a empréstimos da autoridade monetária, não significa que esta não possa influenciar o processo endógeno de criação de moeda de crédito em que se baseia o presente modelo. Aqui, porém, essa influência se dá em nível de preço, por meio da dosagem do juro básico, não de restrições quantitativas. Da mesma forma, a assumida endogeneidade da moeda de crédito não implica a impossibilidade de os próprios bancos influenciarem o acesso efetivo a ela. No modelo deste artigo, entretanto, essa influência é exercida em nível de restrições de acesso ao crédito via preço, não via quantidade. Análises detalhadas das visões pós-keynesianas sobre a endogeneidade monetária podem ser encontradas em MEIRELLES $(1995,1998)$.

4 Noutros termos, o presente artigo não pretende tratar diretamente da maneira como a renda financeira se divide entre rentistas e banqueiros. Embora diferenças entre o montante de recursos captados pelos bancos com os rentistas e o montante emprestados pelos banqueiros ao setor produtivo em um dado período se refletirão na forma como a renda financeira se dividirá entre rentistas e banqueiros, não afetarão, porém, o total dessa renda. Se os bancos captarem mais que o necessário, parcela da renda auferida com o mark-up bancário será repassada aos rentista para remunerar o excesso de captação; caso contrário, parcela adicional de suas próprias reservas será utilizada e os bancos receberão uma maior parte da renda financeira. Porém, os detalhes deste processo e a forma da divisão dessa renda não são focalizados pelo presente modelo e, dadas as hipóteses assumidas, também não afetam os seus resultados, posto que não modificam o total da renda financeira e, como assumido acima, a propensão a poupar dos capitalistas financeiros é a mesma, independente de sua classificação como rentistas ou banqueiros. 


$$
\delta=\frac{D}{K}
$$

onde $D$ representa a dívida do setor produtivo com o setor financeiro. Portanto, a variação do grau de endividamento ao longo do tempo pode ser obtida pela diferenciação da eq. (5):

$$
\frac{d \delta}{d t}=\dot{\delta}=\frac{\dot{D}}{K}-\delta g
$$

onde $\dot{D}$ é a variação da dívida ao longo do tempo e, assumindo-se que o capital não está sujeito a depreciação, $g$ é a taxa de crescimento do estoque de capital e, portanto, a taxa de crescimento dessa economia que produz um único bem. ${ }^{5}$

\section{O COMPORTAMENTO DO MODELO NO CURTO PRAZO}

O curto prazo é definido como sendo o período de tempo em que a taxa de juros, $i$, o salário real, $V$, a relação trabalho-produto, $a$, e, portanto, a parcela dos lucros na renda, $(1-V a)$, além do estoque de dívida do setor produtivo, $D$, o estoque de capital físico, $K$, e, portanto, o grau de endividamento das firmas, $\delta$, estão todos predeterminados. Posto que as decisões de produção das firmas são reguladas pelo princípio da demanda efetiva, estando elas operando sob condições de excesso de capacidade, a equalização macroeconômica entre oferta e demanda é gerada por meio de variações no nível de produto e, portanto, na utilização da capacidade produtiva. Em termos formais, a aludida equalização no mercado de bens pode ser assim representada:

$$
X=\left(1-s_{p}\right)[(1-V a) X-i D]+\left(1-s_{f}\right) i D+V a X+I
$$

5 Posto que focaliza o curto prazo, o presente modelo não formaliza a dinâmica da taxa de juros e suas implicações em nível de estabilidade intertemporal do sistema. Em LIMA \& MEIRELLES (2003), por sua vez, o mark-up bancário varia negativamente com a taxa de lucro sobre o capital físico, que serve de medida da capacidade potencial de pagamento das firmas, e positivamente com a taxa de inflação. Diferentemente do modelo aqui desenvolvido, portanto, os comportamentos estático e dinâmico do sistema são analisados para ambas as possibilidades de utilização da capacidade, plena e abaixo dela, o que torna possível a multiplicidade de equilíbrios dinâmicos para as variáveis endógenas. Em LIMA \& MEIRELLES (2003), entretanto, a dinâmica do endividamento das firmas assim como sua expressão em termos da taxonomia minskyana não são modeladas, embora o seja a variabilidade da parcela dos lucros totais na renda, o que é feito via incorporação de uma dinâmica inflacionária governada por um mecanismo endógeno de conflito distributivo entre trabalhadores e capitalistas. Em LIMA \& MEIRELLES (2004), por seu turno, é desenvolvido um modelo macrodinâmico de utilização e crescimento da capacidade produtiva, no qual o endividamento das firmas - e a fragilidade financeira da economia - é modelado. Entre outros resultados, mostrase que é possível relacionar as condições de estabilidade do sistema dinâmico formado pelas variáveis taxa de juros e endividamento das firmas ao tipo de regime minskyano - hedge, especulativo ou Ponzi - prevalecente. 
onde $I$ é o nível de investimento das firmas e iD é o serviço de sua dívida acumulada, o qual representa, portanto, a renda do setor financeiro. Os três primeiros termos do lado direito da eq. (7), por seu turno, representam, respectivamente, os níveis de consumo dos capitalistas produtivos, dos capitalistas financeiros e dos trabalhadores, conforme assumido anteriormente em termos de comportamento de poupança. Como proporção do estoque de capital, portanto, a poupança agregada, $g^{s}$, é dada por:

$$
g^{s}=s_{p} r+\left(s_{f}-s_{p}\right) i \delta
$$

As equações (7) e (8) indicam os possíveis efeitos da diferença de padrão de consumo e poupança dos capitalistas do setor produtivo e do setor financeiro sobre o valor de equilíbrio de curto prazo da atividade produtiva. Posto, porém, que o principal objetivo do modelo ora desenvolvido é analisar o endividamento das firmas com o setor financeiro e sua relação com os regimes minskyanos de financiamento, esses possíveis efeitos não serão considerados. Logo, assume-se a mesma propensão a poupar para o conjunto dos capitalistas, $s=s_{f}=s_{p}$, o que resulta na versão original da chamada equação de Cambridge:

$$
g^{s}=s r
$$

Quando normalizada pelo estoque de capital e simplificada, a condição de equilíbrio de curto prazo da atividade produtiva, eq. (7), torna-se então:

$$
s(1-V a) u=g^{d}
$$

Portanto, a eq. (10) é uma representação alternativa da condição de equilíbrio de curto prazo da atividade produtiva, expressa agora em termos de igualdade entre poupança e investimento, conforme as eqs. (4) e (9). A existência de capacidade ociosa permite que as firmas concretizem seus planos de acumulação de capital, com a utilização da capacidade ajustando-se então para eliminar eventuais excessos de demanda ou de oferta. Substituindo as expressóes para o investimento desejado das firmas e para a taxa de lucro total, eqs. (1) e (4), respectivamente, na eq. (10), pode-se obter a solução de equilíbrio de curto prazo de $u$, dados os níveis de $i, V, \delta, \delta_{c}$ e parâmetros do modelo:

$$
u^{*}=\frac{\alpha-\gamma i-\varphi\left(\delta-\delta_{c}\right)}{(s-\beta)(1-V a)}
$$

Em termos de estabilidade, assumimos um mecanismo de ajuste keynesiano de acordo com o qual a utilização da capacidade varia positivamente com qualquer excesso de demanda no mercado de bens: 
$\dot{u}=d u / d t=\phi\left[g^{d}-g^{s}\right]=\phi\left[\alpha+\beta(1-V a) u-\dot{i}-\varphi\left(\delta-\delta_{c}\right)-s(1-V a) u\right]$

onde $\phi>0$ é a velocidade (constante) de ajustamento da utilização da capacidade produtiva. Portanto, a estabilidade do valor de equilíbrio de curto prazo de $u$ requer $d \dot{u} / d u<0$, ou seja, $s>\beta$. Em palavras, a estabilidade de $u^{*}$ requer que a poupança agregada seja mais sensível que o investimento desejado a variações na utilização da capacidade, o que assumimos no que segue. Dado que a parcela total dos lucros na renda está restrita ao intervalo $[0,1]$, assumimos ainda a positividade do numerador da eq. (11), o que garante a ocorrência somente de valores positivos para $u^{*}$.

O valor de equilíbrio de curto prazo da taxa de lucro total da economia é obtido pela substituição da eq. (11) na eq. (4), o que gera:

$$
r^{*}=\frac{\alpha-\gamma i-\varphi\left(\delta-\delta_{c}\right)}{(s-\beta)}
$$

Por sua vez, o equilíbrio de curto prazo da taxa de crescimento da economia é obtido pela substituição da eq. (13), seja na eq. (1) ou na eq. (9), o que de qualquer forma gera:

$$
g^{*}=\frac{s\left[\alpha-\gamma i-\varphi\left(\delta-\delta_{c}\right)\right]}{(s-\beta)}
$$

Dado que a estabilidade do equilíbrio de curto prazo de $u^{*}$ requer $s>\beta$, bem como que se assumiu a positividade do numerador de $u^{*}$, a eq. (11) revela que um aumento no salário real, ao transferir renda para os trabalhadores, eleva o consumo agregado e, portanto, promove uma maior utilização da capacidade produtiva instalada. Por seu turno, as eqs. (13) e (14) indicam, respectivamente, que um aumento no salário real, embora eleve a utilização da capacidade instalada, não altera as taxas de lucro e de crescimento da economia, posto que promove uma redução de igual magnitude na parcela dos lucros na renda. ${ }^{6}$ Essas mesmas equações, por outro lado, revelam, respectivamente, que $d u^{*} / d i=u_{i}^{*}<0, d r^{*} / d i=r_{i}^{*}<0$ e $d g^{*} / d i=g_{i}^{*}<0$. Em palavras, uma taxa de juros mais elevada, ao reduzir o investimento desejado das firmas, gera um valor mais baixo para o equilíbrio de curto prazo da utilização da capacidade produtiva instalada e, assim, finda gerando taxas mais baixas de lucro total e de crescimento da

6 Como pode ser checado por meio da solução do modelo com base nas eqs. (1) e (8), partindo-se de uma situação em que os dois grupos de capitalistas tenham o mesmo comportamento de poupança, uma elevação (redução) na propensão a poupar dos capitalistas financeiros promoverá, ceteris paribus, uma redução (elevação) na utilização da capacidade produtiva, posto que reduzirá (elevará) a demanda efetiva. Pela mesma razão, a comparação entre as respectivas expressões revelará que essa elevação (redução) na propensão a poupar dos capitalistas financeiros reduzirá (elevará) as taxas de lucro total e de crescimento. 
economia. ${ }^{7}$ Por seu turno, observa-se que a um grau de endividamento efetivo $\delta$ (desejado $\delta_{c}$ ) mais elevado corresponde um menor (maior) investimento desejado das firmas e, portanto, menores (maiores) taxas de utilização da capacidade produtiva, lucro total e crescimento econômico.

\section{ENDIVIDAMENTO E REGIMES DE FINANCIAMENTO}

A partir da identidade de fluxo de caixa para as firmas apresentada por Foley (2003), é possível colocar a taxonomia minskyana em uma forma adequada aos propósitos do presente modelo:

$$
R+B \equiv I+F
$$

onde $R$ representa as receitas líquidas de operação das firmas, $B$ os novos empréstimos, $I$ o investimento e $F$ o serviço da dívida contraída pelas firmas anteriormente. O valor dos novos empréstimos, $B$, representa a variação da dívida ao longo do tempo, de forma que:

$$
\dot{D}=B=I+F-R
$$

Uma taxonomia minskyana pode ser formalizada a partir do fluxo de caixa das firmas da seguinte forma:

$$
\text { Financiamento hedge: } \quad R \geq I+F \text { ou } B \leq 0
$$

Financiamento especulativo: $R<I+F$ ou $I>B>0$

$$
\text { Financiamento Ponzi: } \quad R \leq F \text { ou } B \geq I
$$

Uma vez que os investimentos das firmas são acréscimos ao seu estoque de capital prévio, com a taxa de crescimento dada por $g=I / K$, que $R$ é o lucro líquido total na economia considerada, de forma que a taxa de lucro total pode ser expressa como $r=R / K$, que a taxa de juros pode ser contabilizada como a razão do serviço da dívi-

7 Como pode ser checado na esteira da nota anterior, um comportamento diferenciado de poupança entre os dois grupos de capitalistas poderia reverter esses resultados de estática-comparativa. Enquanto um aumento no salário real continuaria a afetar positivamente a utilização da capacidade e a manter inalteradas as taxas de lucro total e de crescimento, um aumento nos juros poderia ter um impacto positivo sobre estas últimas. Caso a propensão a poupar dos capitalistas produtivos fosse superior à dos produtivos, uma elevação nos juros continuaria a gerar uma queda nas taxas de utilização da capacidade produtiva, lucro total e crescimento. Caso a superioridade fosse da propensão a poupar dos capitalistas produtivos, uma elevação nos juros geraria uma redistribuição de lucros que, ao favorecer o grupo de menor propensão a poupar, elevaria o consumo, e caso o fizesse em magnitude superior à queda simultânea no investimento desejado, poderia gerar uma elevação na demanda efetiva e, portanto, nas taxas de utilização da capacidade, lucro total e crescimento. 
da pelo seu estoque, o que resulta em $i=F / D$, e considerando, por fim, que o grau de endividamento das firmas pode ser expresso como uma proporção do estoque de capital por meio da relação $\delta=D / K$, a presente taxonomia minskyana pode ser redefinida em qualquer das duas formas apresentadas abaixo:

Tipo de financiamento

\begin{tabular}{lll}
\hline Hedge & $r-i \delta \geq g$ & $r_{p} \geq g$ \\
Especulativo & $r-i \delta<g$ & $r_{p}<g$ \\
Ponzi & $r-i \delta \leq 0$ & $r_{p} \leq 0$ \\
\hline
\end{tabular}

Neste conjunto de equações, a taxa de lucro total, $r$, é desagregada nas taxas de lucro do setor produtivo e do setor financeiro $\left(r \equiv r_{p}+r_{f}=r_{p}+i \delta\right)$, correspondendo esta última exatamente ao serviço da dívida das firmas, o qual representa uma dedução do lucro total da economia gerado pelo setor produtivo, conforme a eq. (3).

As equações acima indicam então que a definição do tipo de regime de financiamento das firmas é obtida pela comparação da taxa de lucro do setor produtivo com a taxa de crescimento da economia. Fica também claro que o lucro do setor produtivo é uma função não só do fluxo de lucro de toda a economia, incorporado via taxa de lucro total, $r$, mas também do serviço da dívida, $i \delta$, que reflete os efeitos da taxa de juros e do endividamento passado, indicando que a demarcação dos regimes minskyanos pode ser representada no espaço $(i, \delta) .^{8}$

A combinação das inequações derivadas acima com as expressões correspondentes para $r^{*}$ e $g^{*}$, eqs. (13) e (14), respectivamente, permite-nos traçar linhas demarcatórias dos diferentes regimes minskyanos de financiamento no espaço $(i, \delta)$ :

8 De maneira mais geral, MINSKY $(1975,1982)$ define uma unidade hedge como aquela cujos fluxos de caixa operacionais esperados excedem os compromissos de caixa esperados em todos os momentos do tempo. A unidade especulativa, por sua vez, é aquela para a qual, em alguns pontos do tempo, esses compromissos superam aqueles fluxos, enquanto a unidade Ponzi é aquela para a qual essa superação ocorre a maior parte do - ou todo o - tempo. Enquanto uma unidade especulativa tipicamente lida com tal superação por meio da rolagem ou refinanciamento da parcela do serviço do endividamento referente ao principal, a unidade Ponzi normalmente o faz por meio da rolagem ou refinanciamento inclusive dos juros correspondentes. 


$$
\begin{aligned}
& \delta_{h-e}=\frac{(1-s)\left[\alpha-\dot{\lambda}+\varphi \delta_{c}\right]}{(s-\beta) i+(1-s) \varphi} \\
& \delta_{e-p}=\frac{\alpha-\dot{\lambda}+\varphi \delta_{c}}{(s-\beta) i+\varphi}
\end{aligned}
$$

onde $\delta_{h-e}$ e $\delta_{e-p}$ indicam os níveis de grau de endividamento correspondentes às transiçôes de regime minskyano de financiamento de hedge para especulativo e de especulativo para Ponzi, respectivamente, para cada nível de juros selecionado. Estas linhas demarcatórias estão ilustradas na Figura 1 a seguir, indicando que combinaçôes de taxas de juros elevadas e maiores graus de endividamento correspondem ao regime Ponzi de financiamento, enquanto combinações destas variáveis com pelo menos uma delas a um baixo nível de valor absoluto indicam a predominância do regime hedge.

Para fins de comparação, na mesma figura estão também indicadas as linhas obtidas com uma função investimento independente do nível de endividamento, ou seja, com $\varphi=0$. Como se observa por esta figura, a formalização dessa concepção de risco crescente na função investimento desloca as linhas demarcatórias para a direita quando o grau de endividamento é menor que o crítico e as desloca para a esquerda para valores maiores de endividamento, alterando as regióes de acordo com tais deslocamentos. As linhas demarcatórias incorporando ou não essa noção de risco crescente cruzam-se exatamente no valor de grau de endividamento crítico. Cabe observar que uma possibilidade alternativa de definir a função investimento, incorporando a restrição do risco crescente para níveis de endividamento maiores que o crítico e excluindo a influência do grau de endividamento para níveis de endividamento menores que o crítico $(\varphi=0$ para $\delta_{c}<0$ e $\varphi>0$ para $\left.\delta_{c} \geq 0\right)$, geraria linhas demarcatórias com uma descontinuidade no valor de $\delta=\delta_{c}$ e constituídas pelas curvas mais à esquerda apresentadas na figura a seguir. 
FIGURA 1 - REGIMES MINSKTANOS NO ESPAÇO (TAXA DE JUROS - GRAU DE ENDIVIDAMENTO)

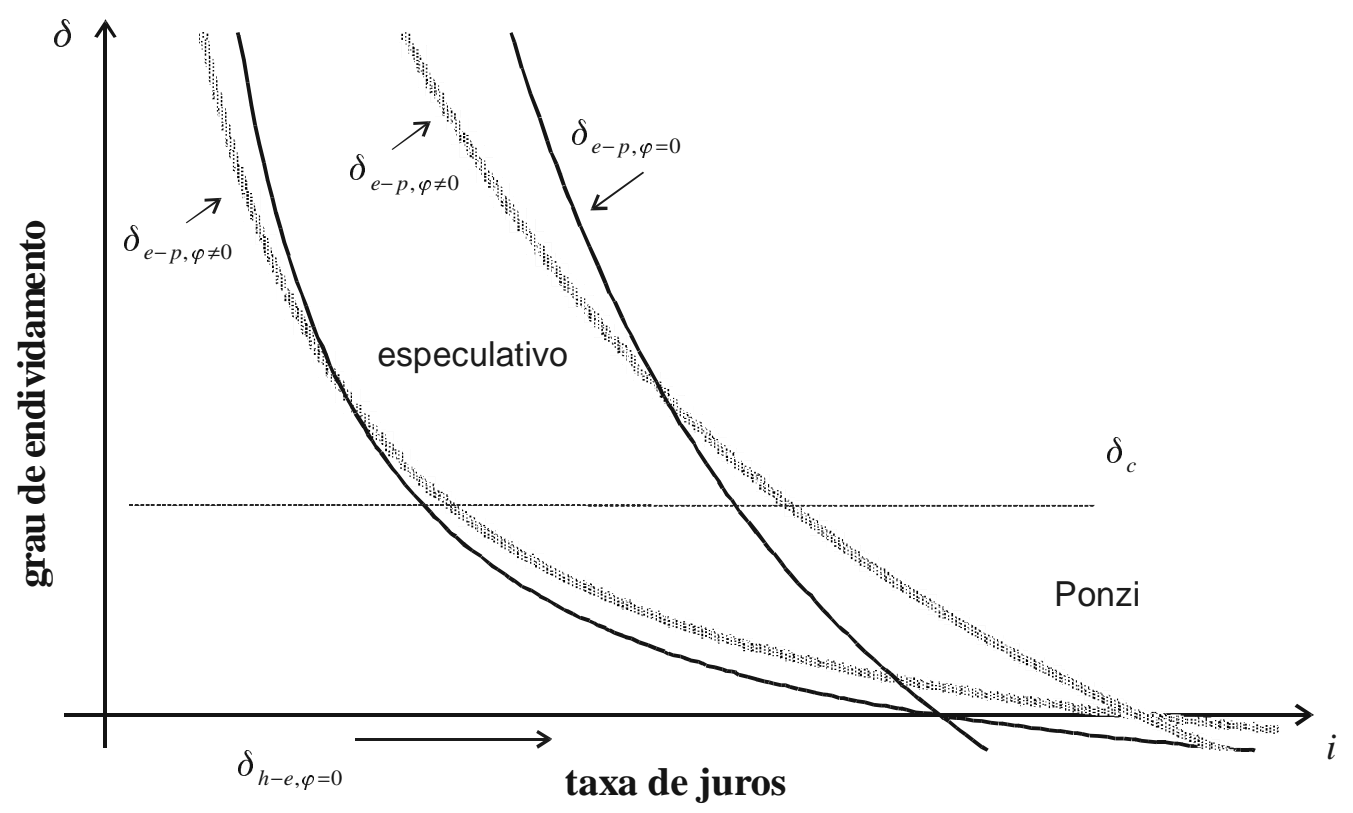

Uma maneira interessante de discussão da influência dos parâmetros do modelo sobre a tendência desta economia estilizada a operar sob um ou outro regime minskyano é analisar as diferentes regióes no espaço $(i, \delta)$ associadas a cada um desses regimes. Para tanto, deve-se inicialmente delimitar a região de validade do modelo nesse espaço. Além da exigência usual de que os valores de juros e endividamento sejam não-negativos, tais variáveis devem ser restringidas ainda no que tange a seus valores máximos, dada a necessidade de obtenção de valores não-negativos para o valor de equilíbrio da utilização da capacidade produtiva. Os cálculos que seguem foram feitos respeitando-se essas restrições.

A partir das linhas demarcatórias derivadas anteriormente e dessas restrições quanto aos valores da taxa de juros e do grau de endividamento, é possível então obter a área total correspondente à região de validade do modelo, assim como as áreas referentes a cada um dos diferentes regimes minskyanos de financiamento. A área total para a situação em que a noção de risco crescente não é incorporada, representada por $A_{T, \varphi=0}$, pode ser obtida pela integração indicada abaixo, a qual resulta na eq. (22):

$$
A_{T, \varphi=0}=\int_{0}^{1} \frac{\alpha}{\gamma} \mathrm{d} \delta
$$




$$
A_{T, \varphi=0}=\frac{\alpha}{\gamma}
$$

Por sua vez, a área total para o caso em que a presente especificação do risco crescente é incorporada, representada por $A_{T, \varphi>0}$, pode ser obtida pela integração indicada a seguir, que resulta na eq. (23):

$$
\begin{aligned}
& A_{T, \varphi>0}=\int_{0}^{1} \frac{\alpha-\varphi\left(\delta-\delta_{c}\right)}{\gamma} \mathrm{d} \delta \\
& A_{T, \varphi>0}=\frac{\alpha+\varphi \delta_{c}-\varphi / 2}{\gamma}
\end{aligned}
$$

Portanto, as áreas totais correspondentes às duas situações em nível de risco crescente do endividamento podem ser comparadas por meio da seguinte expressão:

$$
A_{T, \varphi>0}-A_{T, \varphi=0}=\frac{\varphi \delta_{c}-\varphi / 2}{\gamma}
$$

Vale dizer, a área total da situação com risco crescente será maior que a área sem risco crescente quando $\delta_{c}>0.5$, será menor quando $\delta_{c}<0.5$, e as duas áreas serão iguais quando $\delta_{c}=0.5$. E quando $\delta_{c}>0.5$, por exemplo, a área total da situação com risco crescente será tanto maior que área total sem risco crescente quanto maior o parâmetro $\varphi$, que mede a sensibilidade do investimento desejado em relação ao hiato de endividamento. Por outro lado, a área total da situação com risco crescente será tanto maior que a área sem risco crescente quanto menor o parâmetro $\gamma$, que mede a sensibilidade do investimento desejado em relação à taxa de juros.

Seguindo procedimento semelhante para a região à esquerda da correspondente linha demarcatória hedge-especulativa, é possível então obter a área hedge para a situação com risco crescente, representada por $A_{H, \varphi>0}$ :

$$
\begin{aligned}
& A_{H, \varphi>0}=\int_{0}^{1} \frac{(1-s)\left[\alpha-\varphi\left(\delta-\delta_{c}\right)\right]}{[(s-\beta) \delta+\gamma(1-s)]} \mathrm{d} \delta \\
& A_{H, \varphi>0}=(1-s)\left[\frac{\left(\alpha+\varphi \delta_{c}\right)(s-\beta)+\varphi \gamma(1-s)}{(s-\beta)^{2}}\right] \ln \left[1+\frac{(s-\beta)}{\gamma(1-s)}\right]-\frac{\varphi(1-s)}{(s-\beta)}
\end{aligned}
$$

Por sua vez, a área hedge para a situação em que o risco crescente não é incorporado, representada por $A_{H, \varphi=0}$, é dada por: 


$$
A_{H, \varphi=0}=\frac{\alpha(1-s)}{(s-\beta)} \ln \left[1+\frac{(s-\beta)}{\gamma(1-s)}\right]
$$

Portanto, as áreas hedge correspondentes às duas situações em nível de risco crescente do endividamento podem ser comparadas por meio da seguinte expressão:

$$
A_{H, \varphi>0}-A_{H, \varphi=0}=(1-s)\left[\frac{\varphi \delta_{c}(s-\beta)+\varphi \gamma(1-s)}{(s-\beta)^{2}}\right] \ln \left[1+\frac{(s-\beta)}{\gamma(1-s)}\right]-\frac{\varphi(1-s)}{(s-\beta)}
$$

Vale dizer, para que $A_{H, \varphi>0}-A_{H, \varphi=0} \geq 0$, a seguinte condição deve ser satisfeita:

$$
\delta_{c} \geq \frac{1}{\ln \left[1+\frac{(s-\beta)}{\gamma(1-s)}\right]}-\frac{1}{\frac{(s-\beta)}{\gamma(1-s)}}
$$

Pode-se demonstrar que o termo à direita na inequação acima, denominado $\delta_{c, r e f . a}$, varia no seguinte intervalo: ${ }^{9}$

$$
0 \leq \delta_{c, r e f . a}=\frac{1}{\ln \left[1+\frac{(s-\beta)}{\gamma(1-s)}\right]}-\frac{1}{\frac{(s-\beta)}{\gamma(1-s)}} \leq 0,5
$$

Vale dizer, para valores de endividamento desejado tais que $\delta_{c}>\delta_{c, \text { ref.a }}$, a área hedge da situação com risco crescente torna-se maior que a área hedge daquela sem risco crescente. Por outro lado, temos que:

$$
\frac{\partial\left(A_{H, \varphi>0}-A_{H, \varphi=0}\right)}{\partial \delta_{c}}=\frac{\varphi(1-s)}{(s-\beta)} \ln \left[1+\frac{(s-\beta)}{\gamma(1-s)}\right]>0
$$

Vale dizer, a área hedge da situação com risco crescente começa menor para baixos valores de $\delta_{c}$, igualando-se àquela da situação sem risco crescente quando $\delta_{c}=\delta_{c, \text { ref.a }}$. Para valores de endividamento desejado tais que $\delta_{c}>\delta_{c, \text { ref.a } a}$, por sua vez, a área hedge da situação com risco crescente torna-se maior que a da situação sem risco crescente.

A expressão que representa a soma das áreas hedge e especulativa para a situação com risco crescente do endividamento é apresentada a seguir, eq. (31). Para obter somente a área da região especulativa, portanto, deve-se subtrair da equação abaixo a parcela da área hedge dada pela equação anterior correspondente.

9 Cabe notar que a função $f(x)=\frac{1}{\ln [1+x]}-\frac{1}{x}$ tem derivada $f^{\prime}(x)=\frac{-1}{(\ln [1+x])^{2}(1+x)}+\frac{1}{x^{2}}<0$ e limites $\lim _{x \rightarrow \infty} f(x)=0$ e $\lim _{x \rightarrow 0} f(x)=0,5$. Este último pode ser obtido pela aplicação, por duas vezes, da regra de L' Hospital. 


$$
A_{H+E, \varphi>0}=\left[\frac{\left(\alpha+\varphi \delta_{c}\right)(s-\beta)+\varphi \gamma}{(s-\beta)^{2}}\right] \ln \left[1+\frac{(s-\beta)}{\gamma}\right]-\frac{\varphi}{(s-\beta)}
$$

Portanto, é possível comparar a soma das áreas hedge e especulativa para ambas as situações, a saber, com risco crescente $\left(A_{H+E, \varphi>0}\right)$ e sem risco crescente $\left(A_{H+E, \varphi=0}\right)$, com base na seguinte expressão:

$$
A_{H+E, \varphi>0}-A_{H+E, \varphi=0}=\left[\frac{\varphi \delta_{c}(s-\beta)+\varphi \gamma}{(s-\beta)^{2}}\right] \ln \left[1+\frac{(s-\beta)}{\gamma}\right]-\frac{\varphi}{(s-\beta)}
$$

Para que $A_{H+E, \varphi>0}-A_{H+E, \varphi=0} \geq 0$, portanto, a seguinte condição deve ser satisfeita:

$$
\delta_{c} \geq \frac{1}{\ln \left[1+\frac{(s-\beta)}{\gamma}\right]}-\frac{1}{\frac{(s-\beta)}{\gamma}}=\delta_{c, r e f . b}
$$

Note-se que esta inequação é similar à anterior, (28), somente se diferenciando pela ausência do termo $(1-s)$, o qual apenas altera a velocidade de se alcançar os limites à medida que $(s-\beta) / \gamma$ muda de valor. Em princípio, porém, os mesmos resultados da nota anterior são validos aqui também. Logo, temos:

$$
0 \leq \delta_{c, r e f . b}=\frac{1}{\ln \left[1+\frac{(s-\beta)}{\gamma}\right]}-\frac{1}{\frac{(s-\beta)}{\gamma}} \leq 0,5
$$

com que, para graus de endividamento desejado tais que $\delta_{c}>\delta_{c, \text { ref. } b}$, a soma das áreas hedge e especulativa da situação com risco crescente torna-se maior que a soma correspondente da situação sem risco crescente. De maneira igualmente semelhante, temos que:

$$
\frac{\partial\left(A_{H+E, \varphi>0}-A_{H+E, \varphi=0}\right)}{\partial \delta_{c}}=\frac{\varphi}{(s-\beta)} \ln \left[1+\frac{(s-\beta)}{\gamma}\right]>0
$$

Nesse sentido, os resultados derivados acima nos permitem concluir que, para valores de endividamento desejado elevados, o deslocamento das linhas demarcatórias ocorre de tal forma que possibilita um número maior de combinações de taxa de juros e endividamento compatíveis com a maior robustez financeira característica do regime hedge e, em seguida, do regime especulativo. A razão para a ocorrência desse impacto positivo parece estar, conforme captado pela função investimento incorporando o risco crescente, na ampliação (redução) do estímulo ao investimento para baixos (elevados) valores de grau de endividamento. 


\section{REPRISE DAS CONCLUSÕES}

O presente artigo desenvolveu um modelo macroeconômico de curto prazo na tradição pós-keynesiana de abordagem da acumulação de capital produtivo e da distribuição funcional da renda, no qual a oferta de crédito é endógena e o grau de endividamento do setor produtivo é explicitamente modelado. O fluxo de lucro monetário oriundo da utilização do capital físico instalado é dividido entre os capitalistas produtivos e financeiros, os quais adotam um padrão de poupança e consumo diferenciado em relação àquele dos trabalhadores, o que torna então a demanda efetiva $\mathrm{e}$, portanto, as taxas de utilização da capacidade, lucro total e crescimento, dependentes da distribuição funcional da renda.

Após o estabelecimento das condiçóes formais que definem os regimes minskyanos de financiamento, analisou-se a influência dos parâmetros do investimento desejado das firmas e da propensão a poupar dos capitalistas sobre a propensão do setor produtivo a cada um desses regimes, tanto na presença como na ausência de uma certa especificação do risco crescente do endividamento. Esta especificação, inspirada no princípio do risco crescente elaborado por Michal Kalecki, procurou representar a concepção de que um grau de endividamento superior (inferior) a um grau crítico predeterminado, com ambos expressos como relação entre dívida acumulada e estoque de capital físico, gera um impacto negativo (positivo) sobre os planos de acumulação de capital físico das firmas. Sendo assim, o modelo aqui desenvolvido associou um risco crescente não diretamente ao volume de investimento em si, como na elaboração original de Kalecki, mas, sim, ao endividamento das firmas como proporção do estoque de capital físico instalado e, portanto, indiretamente ao nível de investimento por elas desejado como proporção desse mesmo estoque.

Mostrou-se que um aumento no salário real, ao transferir renda para os trabalhadores, eleva o consumo agregado e, assim, promove uma maior utilização da capacidade produtiva instalada. Por seu turno, um aumento no salário real, embora eleve a utilização da capacidade, não altera as taxas de lucro e de crescimento da economia, posto que promove uma redução de igual magnitude na parcela dos lucros na renda. Uma vez que os capitalistas produtivos e financeiros poupam a mesma fração de sua participação nos lucros, um aumento na taxa de juros, ao afetar negativamente o investimento das firmas, reduz os valores de equilíbrio de curto prazo da utilização da capacidade produtiva e, portanto, finda reduzindo as taxas de lucro total e de crescimento econômico. Já uma elevação na taxa de juros, ao reduzir o investimento desejado, provoca uma queda nas taxas de utilização da capacidade, lucro total e crescimento da economia. Por seu turno, a um grau de endividamento efetivo (desejado) mais elevado corresponde um menor (maior) investimento desejado e, portanto, menores (maiores) taxas de utilização da capacidade produtiva, lucro total e crescimento econômico. 
Em nível de influência do endividamento sobre a tendência da economia a operar sob um ou outro regime minskyano de financiamento, observou-se que para valores elevados de endividamento desejado como máximo pelas firmas, maior o número de combinações de taxa de juros e nível de endividamento compatíveis com a maior robustez financeira característica dos regime hedge e, em menor grau, especulativo.

Em sintonia com a abordagem minskyana do financiamento, portanto, uma importante implicação analítica da especificação da noção de risco crescente incorporada ao modelo deste artigo é o seguinte paradoxo: caso as firmas, na tentativa de reduzir seu endividamento efetivo, venham a reduzir seu endividamento desejado como máximo, a conseqüente queda na utilização da capacidade produtiva, no crescimento e, portanto, nos lucros, poderá vir a elevar sua fragilidade financeira.

\section{REFERÊNCIAS BIBLIOGRÁFICAS}

DUTT, A. K. Interest rate policy in LDCs: a Post Keynesian view. Journal of Post Keynesian Economics, v. 13, n. 2, 1990-91.

. On the long-run stability of capitalist economies: implications of a model of growth and distribution. In: DUTT, A. K. (ed.), New directions in analytical political economy. Aldershot: Edward Elgar, 1994.

FOLEY, D. Financial fragility in developing economies. In: DUTT, A. K.; ROS, J. (eds.), Development economics and structuralist macroeconomics. Aldershot: Edward Elgar, 2003.

KALECKI, M. Principle of increasing risk. Economica, 4, November 1937.

. Selected essays on the dynamics of the capitalist economy. Cambridge: Cambridge University Press, 1971.

LIMA, G. T. Kalecki's principle of increasing risk. In: O'HARA, P. (ed.), Encyclopedia of political economy. London: Routledge, 1999.

. Market concentration and technological innovation in a dynamic model of growth and distribution. Banca Nazionale del Lavoro Quarterly Review, v. LIII, n. 215, December 2000.

. Endogenous technological innovation, capital accumulation and distributional dynamics. Metroeconomica, v. 55, n. 4, November 2004.

LIMA, G. T.; MEIRELLES, A. J. A. Endogenous banking markup, distributional conflict and capacity utilization. Metroeconomica, v. 54, n. 2\&3, May/September 2003 .

- A macrodynamics of debt regimes, financial instability and growth. Paper presented at The Eight International Post Keynesian Workshop, Kansas City, Missouri, USA, June 2004. 
MEIRELLES, A. J. Moeda endógena e teoria monetária da produção. Revista de Economia Politica, v. 15, n. 3, 1995.

. Moeda e produção: uma análise da polêmica pós-keynesiana sobre a endogenia monetária. Campinas: Mercado de Letras; São Paulo: Fapesp, 1998.

MINSKY, H. John Maynard Keynes. New York: Columbia University Press, 1975.

. Can "it" happen again? Essays on instability and finance. New York: M. E. Sharpe, 1982.

ROBINSON, J. Essays in the theory of economic growth. London: Macmillan, 1962.

ROWTHORN, B. Demand, real wages and economic growth. Thames Papers in Political Economy, Autumn 1981.

Cabem agradecimentos - e a correspondente isenção de responsabilidade - a dois pareceristas anônimos por observações úteis. Vale registro também nosso agradecimento ao $\mathrm{CNPq}$ pela assistência recebida no âmbito do Programa de Bolsas de Produtividade em Pesquisa.

e-mail: giltadeu@usp.br

e-mail: tomze@ceres.fea.unicamp.br

(Recebido em fevereiro de 2004. Aceito para publicação em janeiro de 2005). 